\title{
RNA interference therapeutics for cancer: Challenges and opportunities (Review)
}

\author{
ROOP SINGH BORA ${ }^{1,3}$, DIKSHI GUPTA ${ }^{1,4}$, \\ TRILOCHAN KANWALJIT SINGH MUKKUR ${ }^{2}$ and KULVINDER SINGH SAINI ${ }^{1,5}$ \\ ${ }^{1}$ Department of Biotechnology, Ranbaxy Laboratories Limited, Gurgaon-122 015, Haryana, India; \\ ${ }^{2}$ School of Biomedical Sciences, Curtin Health Innovation Research Institute, Western Australian Biomedical \\ Research Institute, Curtin University, Bentley Campus, Perth, Western Australia 6102, Australia
}

Received December 20, 2011; Accepted March 20, 2012

DOI: $10.3892 / \mathrm{mmr} .2012 .871$

\begin{abstract}
RNA interference (RNAi) is a sequence-specific, post-transcriptional gene silencing mechanism in animals and plants, which is mediated by double-stranded RNA (dsRNA). There has recently been an increasing interest in harnessing the gene silencing activity of dsRNA to develop novel drugs for the treatment of various diseases, such as cancer, neurological disorders, age-related macular degeneration and viral infections. Small interfering RNA (siRNA)-based drugs have distinct advantages over conventional small molecule or protein-based drugs, including high specificity, higher potency and reduced toxicity. However, there are several technical obstacles to overcome before siRNA-based drugs reach the clinic. Delivery of siRNA to the target tissues and stability in the serum remain a major challenge and are the main focus of current research and development efforts. This review focused primarily on the progress made in developing RNAi as therapeutics for cancer and the challenges associated with its clinical development. Use of ligands recognizing cell-specific receptors to achieve tumor-specific delivery of siRNA, methods for enhanced siRNA delivery, improving the bioavailability and pharmacokinetic properties of siRNA and reducing the off-target effects and non-specific gene silencing are discussed in the light of current evidence.
\end{abstract}

Correspondence to: Dr Roop Singh Bora, ${ }^{3}$ Present address: Ranbaxy Biologics Division, Ranbaxy Laboratories Limited, Sy. No. 16, Ekarajapura, Hasigala Post, Siddlaghatta Road, Hoskote, Bangalore-562114, Karnataka, India

E-mail: roop.singh@ranbaxy.com

Present address: ${ }^{4}$ Centre for Biomedical Engineering, Indian Institute of Technology Delhi, Hauz Khas, New Delhi 110016, India

Present address: ${ }^{5}$ Research and Development office, Eternal University, Baru Sahib 173101, Himachal Pradesh, India

Key words: RNA interference, short interfering RNA, gene silencing, cancer, short interfering RNA delivery, target specificity

\section{Contents}

1. Introduction

2. RNA interference therapeutics for cancer treatment

3. Strategies for improving the pharmacokinetics of therapeutic small interfering RNA

4. Target specificity

5. Safety issues

6. Conclusions

\section{Introduction}

RNA interference (RNAi) is an evolutionarily conserved process of sequence-specific, post-transcriptional gene silencing in animals and plants, mediated by double-stranded RNA (dsRNA), which is homologous in sequence to the target gene. Gene silencing by dsRNA was first observed in the early 1990s in plants (1). However, the phenomenon of RNAi was first discovered by Fire et al in 1998, who reported that injection of dsRNA into Caenorhabditis elegans resulted in the silencing of the complementary messenger RNA (mRNA) sequence (2). Since the introduced dsRNA molecules blocked the function of the targeted gene, the process was termed 'RNA interference'. It was also observed that dsRNAs, which are several hundred bases in length, not only caused significant gene silencing in Caenorhabditis elegans, but were also more potent and active than the corresponding single-stranded antisense molecules (2). However, subsequent studies established that it was not easy to detect potent and specific RNAi in commonly used mammalian cell lines using large size dsRNA (3-5). The findings of these studies showed that long dsRNA was responsible for inducing interferon response in the mammalian cells by activating the protein kinase PKR and 2', 5'-oligoadenylate synthetase. Activated protein kinase, PKR, inhibited protein translation by phosphorylation of the translation initiation factors elF2. Moreover, activated 2', 5'-oligoadenylate synthetase resulted in non-specific mRNA degradation by activated ribonuclease L. The global shutdown due to non-specific mRNA degradation and inhibition of protein synthesis eventually resulted in cell death (6-8). In their study, Elbashir et al (3) provided the first evidence that 21-23 nucleotide (nt) double-stranded siRNA 
mediates sequence-specific gene silencing in mammalian cells without activating the interferon response. Subsequently, this technology was improvised and successfully applied to perform target-specific gene silencing in adult mouse models (9-11). Short (21-23 nt) siRNAs are usually considered optimal for gene silencing, however, a 27-mer siRNA was able to achieve a 100-fold stronger and more potent gene silencing, compared to a corresponding 21-23 nt sequence (12).

RNAi is initiated by dsRNAs that undergo processing by an endonuclease enzyme known as Dicer. The long fragment of dsRNA is cleaved by Dicer into duplexes with 19 paired nucleotides and two nucleotide overhangs at the two 3'-ends $(13,14)$. These duplexes, referred to as short interfering RNAs (siRNAs), associate with the RNA-induced silencing complex (RISC), a large protein complex ( 160 kDa) comprising of Argonaute (Ago) proteins $(15,16)$. In humans, there are eight members of the Ago family, however, only Ago2 possesses an active catalytic domain for cleavage activity $(17,18)$. Within the RISC, siRNA unwinds and the sense strand is removed and degraded by nucleases. The antisense strand of the siRNA directs RISC to the target mRNA. The cleavage site, which is $\sim 10$ nucleotides from the 5'-end of the siRNA, on the target mRNA, is aligned with the Ago2 PIWI endonuclease domain. Ago2 cleaves the phosphodiester bond on the mRNA and releases the cleaved mRNA fragments that are finally degraded resulting in the gene silencing $(19,20)$. The siRNA-loaded RISC can be recycled for several rounds of the gene silencing process, which makes siRNA extremely attractive for therapeutic interventions (21).

Recently, RNAi has rapidly progressed from bench to bedside with several RNAi-based drugs undergoing clinical trials. Several in vitro and in vivo proof-of-concept studies have shown that almost every human disease with a gain-offunction genetic lesion or overexpression of disease causing gene(s) is a potential target for RNAi-based therapeutics (22). RNAi has shown potential for the treatment of various diseases which are not amenable to small molecule (chemical) drugs or protein-based therapeutics. Several in vivo studies in animal models have shown that RNAi-based drugs can be effective in the treatment of various diseases, such as hypercholesterolemia (23), viral hepatitis (24), Huntington's disease $(25,26)$ and cancer (27-29). Initially, RNAi-based clinical trials focused on the direct localized delivery of siRNA and on validated therapeutic targets, such as vascular endothelial growth factor (VEGF), for the treatment of the wet age-related macular degeneration and the respiratory syncytial virus (RSV) for the treatment of RSV infections (30,31). At present, the RNAi therapeutics being developed for the treatment of age-related macular degeneration require a direct injection of VEGF-specific siRNA into the vitreal cavity to efficiently deliver the siRNA to the eye. RNAi therapeutics for the treatment of RSV infection employ direct delivery of siRNA into the lungs. However, the development of RNAi-based therapeutics for other diseases, particularly cancer, requires a more challenging systemic delivery of siRNA to the target tissues, a major challenge in research and development efforts.

\section{RNA interference therapeutics for cancer treatment}

Cancer is one of the major targets of RNAi-based therapy, as oncogenes, mutated tumor suppressor genes and several other genes contributing to tumor progression are potentially important targets for gene silencing by RNAi. Due to the precise mechanism of action, high specificity and potency of RNAi-mediated gene silencing, there are reduced chances of side-effects that are often associated with chemotherapy drugs. The major advantage of RNAi therapeutics in cancer would be the simultaneous targeting of multiple genes, belonging to different cellular pathways that are involved in tumor progression. The concurrent inhibition of several genes is potentially a more potent and effective way to treat cancer and it would also minimize the probability of multiple drug resistance normally encountered with small molecule-based cancer therapies. Another advantage of RNAi-based therapeutics involves the development of personalized anticancer drugs suitable for a particular patient. Such personalized medicine is likely to be more effective in controlling the cancer, thereby improving the success rate of cancer drugs.

Several potential siRNA targets in cancer have been described in the literature, although proof-of-concept studies in animal models are just beginning to emerge. Judge et al (27) showed that administration of siRNA targeting the essential cell-cycle proteins, such as kinesin spindle protein (KSP) and polo-like kinase 1 (PLK1), exhibited potent antitumor activity in both hepatic and subcutaneous tumor models. KSP is a mitotic spindle motor protein that is involved in chromosome segregation during mitosis. Inhibition of KSP prevents the formation of bipolar mitotic spindles resulting in cell-cycle arrest and induction of apoptosis (32). Similarly, PLK1 is important in mitosis and cytokinesis. Overexpression of PLK1 is observed in several human types of cancer and inhibition of PLK1 activity induces tumor cell apoptosis (33). These studies clearly suggest that siRNA specifically targeting KSP and PLK1 can be developed as a therapy for cancer. Among other cancer-directed approaches is the targeting of pleiotrophin, which effectively reduced tumor growth in mouse xenograft models of glioblastoma multiforme (34).

Protein kinase N3 (PKN3) has been validated as a therapeutic target in cancer, as inhibition of this kinase resulted in the reduction of lymph node metastases in orthotopic prostate cancer models (35). In their study, Aleku et al (36) showed that systemic administration of Atu027, a siRNA-lipoplex targeted against PKN3 in mice, rats and non-human primates, resulted in specific RNAi-mediated silencing of PKN3 expression with significant inhibition of tumor growth and lymph node metastasis. Atu027 also prevented pulmonary metastasis in various animal models of cancer. Atu027 was administered to breast cancer mouse models to evaluate its ability to prevent the spread of cancer to the lungs, and was shown to have a potent inhibitory effect on pulmonary metastasis. Since metastasis is a major cause of high mortality rate among cancer patients, its prevention is critical for the survival and quality of life of the patient. Silence Therapeutics is currently conducting a phase I clinical study of Atu027 for the treatment of advanced solid cancer, which is expected to be completed in 2012.

Calando Pharmaceuticals has recently reported a phase I clinical study of CALAA-01 for the treatment of solid tumor (37). CALAA-01 is a transferrin receptor-targeted nanoparticle encapsulating a non-chemically modified siRNA specific to the M2 subunit of ribonucleotide reductase (RRM2), a gene involved in DNA replication. Upon administration, CALAA-01 
binds to transferrin receptors and releases RRM2-specific siRNA after endocytosis, which inhibits the expression of RRM2 and thus prevents the proliferation of transferrin receptor-expressing tumor cells. Calando Pharmaceuticals has conducted the phase I clinical trials by systemic administration of CALAA-01 to patients with solid tumors. Furthermore, tumor biopsies from melanoma patients following treatment showed the presence of intracellularly localized nanoparticles, and reduction of the RRM2 at the mRNA and protein levels. The Phase I study of CALAA-01 clearly demonstrated that siRNA administered systemically to human patients was able to silence the cancer-associated gene in specifically-targeted tumor cells (37).

Alnylam Pharmaceuticals is currently conducting Phase I clinical trials with ALN-VSP02, a systemically delivered RNAi for the treatment of liver cancer. ALN-VSP02 is a lipid nanoparticle formulation encapsulating two siRNAs specific for VEGF and KSP with antitumor activity. VEGF and KSP are overexpressed in numerous cancer cells and are essential in tumor growth and survival. ALN-VSP02 has been well validated in pre-clinical studies, since its intravenous administration in mouse models of primary and metastatic liver cancer results in a decrease in microvessel density and vascular leakage due to VEGF knockdown, and the simultaneous inhibition of KSP prevents the formation of mitotic spindle, leading to tumor cell death. Preliminary clinical data from the ongoing Phase I trial demonstrated that ALN-VSP02 is well-tolerated in most patients. ALN-VSP02 has shown the potential to sensitize liver cancer to chemotherapy and to treat cancer by itself by inhibiting the proliferation of tumor cells. ALN-VSP02 is the first dual-targeted siRNA molecule targeting two different pathways with two different siRNAs, thereby setting the precedence for future therapies based on targeting multiple genes, thus increasing the therapeutic impact of siRNA drugs in curing cancer. There are currently 5-6 clinical trials in progress, all in Phase I, evaluating the safety and efficacy of siRNA-based drugs for cancer treatment (Table I.)

\section{Strategies for improving the pharmacokinetics of therapeutic short interfering RNA}

The major issue confronting siRNA-based therapeutics for cancer and other diseases is delivering siRNA to the target cell population in vivo. The efficacy of siRNA-based drugs in combating cancer requires potent and effective gene silencing in the tumor cells. Additionally, to achieve effective gene knockdown in vivo requires efficient delivery of siRNA to the target tissues. The highly negative charge of siRNA molecules prevents the efficient uptake of these therapeutic molecules in vivo. In addition, degradation of siRNA in endosomal compartments and its rapid clearance by renal excretion from the blood after the intravenous route would greatly reduce the potency of the siRNA. To achieve efficient delivery of siRNA and therapeutic gene silencing, an ideal drug delivery system needs to protect the siRNA from degradation by nucleases and enhance its stability, prevent non-specific uptake by nontarget tissues and improve the delivery of therapeutic siRNA to the target cells and tissues. Both local and systemic delivery of siRNA to various cells and tissues have been demonstrated pre-clinically (38-42). For localized delivery, administration of unmodified siRNA in simple formulation, such as saline, has resulted in significant gene silencing in a variety of tissues, including the respiratory epithelium, eye and central nervous system (43-47). Systemic delivery of siRNA offers great opportunities and challenges. An unmodified saline-formulated siRNA injected intravenously is subjected to degradation by nucleases in the serum and rapid renal excretion. Thus, any attempt at systemic delivery of siRNA should involve methods for increasing the serum half-life of the siRNA, its distribution to target tissue, its cellular uptake with subsequent intracytoplasmic release without degradation and avoiding off-target gene silencing activity.

Chemical modifications of siRNA have become essential for achieving potent gene silencing activity, since these modifications stabilize siRNA in the serum (48-50). These alterations can be introduced at the 5'- or 3'-terminus, backbone, sugar and nucleobase of siRNA. An ideal modification should enhance the stability of siRNA without affecting its gene silencing activity. Modification of RNA at the 2' position of the ribose ring has been shown to increase siRNA stability by preventing the degradation from endonucleases. These modifications, which include 2'-O-methyl and 2'-deoxy-2'-fluoro, enhance the serum stability of siRNA and increase its in vivo potency (49). Conjugation of siRNA with cholesterol has been shown to enhance the siRNA uptake via receptor-mediated endocytosis or by an increased membrane permeability of the negatively-charged siRNA (51). Soutschek et al (23) reported that conjugation of cholesterol to the siRNA targeting ApoB increased the stability of siRNA in the serum and enhanced its gene silencing activity. It was observed that conjugation of cholesterol to an ApoB-specific siRNA resulted in a significant reduction in renal clearance and a 16 -fold increase in serum half-life, as compared to the unconjugated control, following intravenous administration. More significantly, it also facilitated receptor-mediated uptake of the siRNA specifically into hepatocytes and resulted in a $60 \%$ knockdown of ApoB mRNA in the mouse liver (23). Similarly, cholesterol can also be conjugated to any therapeutic siRNA specific for cancercausing genes to increase its serum half-life and prevent its renal clearance, thereby improving its bioavailability and pharmacokinetic properties. Conjugation of therapeutic siRNA with cholesterol would also facilitate the targeted delivery of siRNA to the liver, leading to the development of an effective therapy for liver cancer.

Another approach for systemic delivery involves the use of stable nucleic acid-lipid particles (SNALPs). This technology encapsulates siRNA in lipid nanoparticles to deliver RNAibased drugs to the target cells or tissues. Efficacy of SNALP technology relies on enhanced permeability and retention due to a long circulation time in the blood. This results in increased bioavailability, leading to the accumulation of these SNALPs at the sites of vascular leaks, including the sites of tumor cell growth. Once at the target site, SNALPs are absorbed by the tumor cells through endocytosis and the siRNA is delivered inside the cell. Judge et al (27) have successfully demonstrated the delivery of siRNA specific to PLK1 to solid tumors in mice using SNALP, which resulted in a $75 \%$ reduction in subcutaneous tumor size. In another pre-clinical study, cationic and neutral lipids comprising the lipid bilayer along with an outer 
Table I. Current status of siRNA-based cancer therapeutics ${ }^{\mathrm{a}}$.

\begin{tabular}{|c|c|c|c|c|c|}
\hline Sponsor & Program & $\begin{array}{l}\text { Target } \\
\text { gene }\end{array}$ & $\begin{array}{l}\text { Mode of } \\
\text { delivery }\end{array}$ & Indication & $\begin{array}{c}\text { Stage of } \\
\text { development }\end{array}$ \\
\hline
\end{tabular}

Calando

Pharmaceuticals

Silence Therapeutics AG Atu027

Silenseed Ltd.

Sataris Pharma and Enzon Pharmaceuticals

Tekmira
PKN3

ALN-VSP02 SiG12D LODER KRAS

EZN-2968

CALAA-01 RRM2

SNALP-PLK

HIF-1,

PLK1
VEGF, KSP Lipid nanoparticle

Transferrin receptor-targeted cyclodextrin-based nanoparticles

Lipoplex-siRNA

Miniature biodegradable polymer matrix survivin

Locked nucleic acid
Lipid nanoparticle
Solid cancer

Phase I

\section{Phase I}

Gastrointestinal, Phase I

lung and other

advanced cancers

$\begin{array}{ll}\text { Liver cancer } & \text { Phase I } \\ \text { Adenocarcinoma } & \text { Phase I } \\ \text { of pancreas } & \end{array}$

Solid cancer with Phase I liver metastases

Cancer

IND approved

${ }^{a}$ All data from published articles (as mentioned in the text), corporate websites and http://www.clinicaltrials.gov. KSP, kinesin spindle protein; PKN3, protein kinase N3; RRM2, M2 subunit of ribonucleotide reductase; VEGF, vascular endothelial growth factor; HIF-1, hypoxia-induced factor; KRAS, V-ki-ras2 Kirsten rat sarcoma viral oncogene homolog; PLK1, polo-like kinase 1; IND, investigational new drug.

hydrophilic coating of polyethylene glycol (PEG) with encapsulated ApoB-specific siRNAs were prepared. Administration of siRNAs containing SNALPs in monkeys reduced the ApoB expression in the liver and significantly lowered cholesterol levels. Moreover, no toxicities were observed, suggesting the proof-of-concept of this technology for systemic delivery of siRNAs (52).

The polyanionic nature of siRNA prevents its penetration into the cell membrane and due to its small size (average size is $<10 \mathrm{~nm}$ ) non-formulated siRNA was reported to be easily excreted by the body, resulting in low bioavailability and poor pharmacokinetic properties of therapeutic siRNA (53-55). To improve the particle size of siRNA and to prevent its degradation by nucleases, nanoparticles $(50-200 \mathrm{~nm})$ were specifically designed to mitigate tumor growth in mouse models (56-58). These nanoparticles, which are formed by conjugating biologically inert polymers directly to siRNA or by preparing liposomes that encapsulate siRNA, were shown to be effective in stabilizing siRNA in the serum. Nanoparticlemediated delivery of siRNA has the potential to improve the pharmacokinetics, pharmacodynamics and biodistribution of therapeutic siRNA, thereby improving the bioavailability of these therapeutic molecules. The size of nanoparticles is crucial for the effective delivery of siRNA to the target tissue. Nanoparticles ranging from 10 to $100 \mathrm{~nm}$ or up to $200 \mathrm{~nm}$ are regarded as optimal, since they are small enough to pass through the cell membrane by receptor-mediated endocytosis, yet large enough to be retained by the body, thereby improving the pharmacokinetics of therapeutic siRNA $(53,58-60)$.

\section{Target specificity}

To improve the delivery of therapeutic siRNA specifically to the tumor cells and avoid the targeting of normal cells, various ligands recognizing cell-specific receptors can be exploited for targeted delivery. Several strategies have been formulated to promote cell type-specific siRNA delivery, including antibodies, ligands and aptamers. Antibodies are an excellent tool for targeted delivery approaches as they recognize specific antigens with extremely high affinity and selectivity. Song et al (61) fused the antigen recognition domain from an antibody fragment (Fab) that recognizes the HIV envelope glycoprotein to a highly positively charged protamine and successfully delivered siRNA-targeting HIV sequences into virally infected $\mathrm{CD}^{+} \mathrm{T}$ cells, thus inhibiting viral replication. In addition, anti-angiogenesis siRNA complexed to the Fab-protamine fusion protein was successfully targeted to subcutaneously implanted tumor cells expressing the HIV envelope following intravenous injection leading to the inhibition of tumor growth (61). Cell type-specific delivery has also been achieved using aptamers, which are highly structured nucleic acid molecules (RNA and DNA) with affinity to a particular target molecule. Aptamers are selected through several rounds of binding to specific cell surface target antigens (62), and individual RNA aptamers can be directly linked to siRNA molecules to generate a chimeric RNA for cell type-specific delivery. An aptamer that binds specifically to the prostate-specific membrane antigen (PSMA) has been shown to efficiently deliver siRNA to prostate cancer cells leading to the regression of prostate tumors in mouse xenograft models $(63,64)$.

Recent studies have shown that several human tumor cells overexpress members of the $\sigma$ receptor family of membrane bound proteins. Li et al (65) demonstrated that liposome nanoparticles coated with the $\sigma$ receptor ligand anisamide and with an encapsulated siRNA specific to epidermal growth factor receptor (EGFR) were able to inhibit growth and metastasis in a mouse xenograft model of lung cancer. Similarly, liposomes coated with transferrin facilitated the delivery of the siRNA-targeting Bcr-Abl fusion gene into leukemia cell lines (66). Transferrin ligand-coated nanoparticles were designed to specifically target Ewing sarcoma 


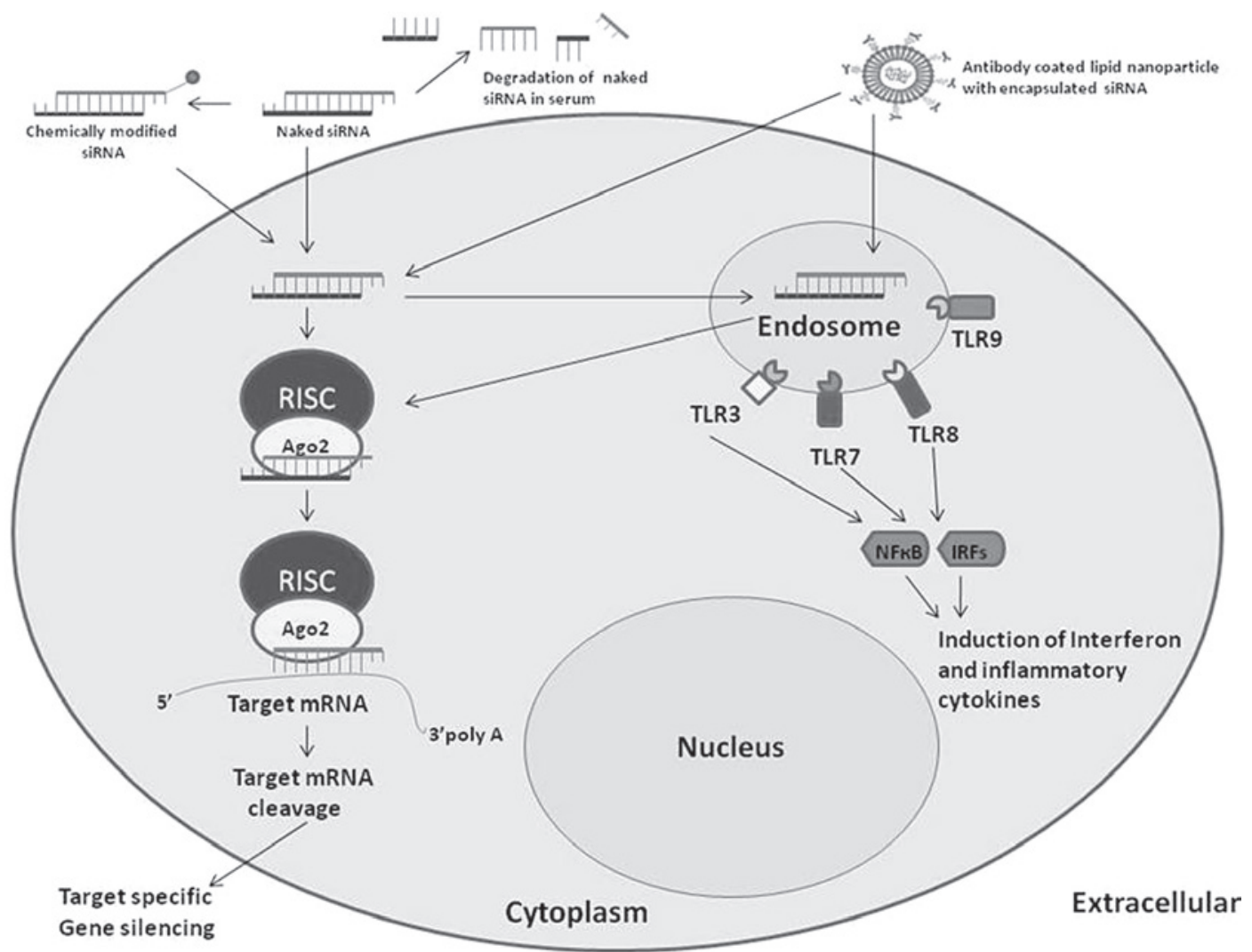

Figure 1. Harnessing the therapeutic potential of RNA interference (RNAi). RNAi is induced by 21-23 nucleotide, double-stranded RNA (dsRNA), which is incorporated into the RNA-induced silencing complex (RISC), a large protein complex comprising Argonaute (Ago) proteins. Within the RISC, siRNA unwinds and the antisense strand of the siRNA directs RISC to the target mRNA. Ago2 cleaves the mRNA resulting in the gene silencing. For localized delivery, administration of unmodified siRNA results in significant gene silencing in a variety of tissues. However, the systemic delivery of unmodified siRNA results in the degradation of siRNA by nucleases in the serum and rapid renal excretion, thus reducing the efficacy of siRNA-based drugs. Chemical modification of siRNA, conjugation of siRNA with cholesterol or encapsulation in nanoparticles increases the stability of siRNA in the serum, improves its bioavailability and enhances its gene silencing activity. To promote cell type-specific siRNA delivery, several strategies have been formulated, including antibodies, ligands and aptamers. However, a growing concern of using siRNA for therapeutic purposes is the activation of an immune response through Toll-like receptor (TLR) pathway resulting in the induction of high levels of inflammatory cytokines. NF- $\mathrm{B}$, nuclear factor- $\mathrm{k}$; IRF, interferon regulatory factor.

tumors and were prepared using cyclodextrin-containing polycations to incorporate negatively-charged siRNA molecules. To improve stability, PEG polymers were attached to the outer surface using terminal adamantine groups. Transferrin ligands were covalently linked to the adamantinePEG chains and $50 \mathrm{~nm}$-sized nanoparticles were generated. The nanoparticle-encapsulated siRNAs specifically targeted the Ewing sarcoma breakpoint region 1-flightless 1 homolog (Ews-Fli1) gene fusion product and inhibited tumor growth in a mouse model (67).

\section{Safety issues}

Besides target-specific siRNA delivery, another major challenge in developing therapeutic strategies using siRNA involves the undesirable off-target effects (68). This effect has been well-characterized using microarray studies of siRNAtransfected cells, in which the expression of various genes was downregulated with increased doses of siRNA (69). The delivery and off-target effects of siRNA-based therapies are linked. Efficient delivery of siRNA to targeted cancer cells would reduce the number of normal cells exposed, favour tumor uptake, thereby reducing the potential off-target effects. In addition, efficient delivery to cancer cells would reduce the therapeutic dose of siRNA to be administered, thus minimizing the potential dose-related adverse effects. Another undesirable side-effect of siRNA-based drugs is the activation of the innate immune system resulting in the induction of high levels of inflammatory cytokines, such as interferon- $\alpha$ (IFN- $\alpha$ ), tumor necrosis factor- $\alpha$ and interleukin-6, which may cause considerable toxicities. While double-stranded RNA longer than $30 \mathrm{nt}$ elicits a strong IFN response through the protein kinase R (70), shorter siRNAs may activate the innate immune system through the Toll-like receptor (TLR) pathway (Fig. 1). In particular, TLR7 and TLR8 receptors for dsRNA are involved in siRNA-induced IFN response. Recent studies reported that siRNAs activate dendritic cells through TLRs, a subset of which, i.e., TLR3, TLR7, TLR8 and TLR9, recognizes exogenously administered siRNAs $(71,72)$. Hornung et al (71) identified a 9 nt sequence in a siRNA that activated the TLR7 and elicited an immune response. Similarly, Judge et al (73) identified such immunostimulatory motifs in siRNAs. These observations are critical for designing therapeutic siRNAs with reduced potential to cause immunostimulatory effects. Experimental evidence has established that RNAi is a revolutionary tool for the treatment of several diseases, however, due caution is necessary when developing strategy for siRNAbased therapeutics. 


\section{Conclusions}

There is an unmet medical need for effective cancer therapies that block the progression of solid tumors and prevent metastasis. Recently, siRNA-based therapeutics have generated a lot of interest in the development of novel and more potent drugs for the treatment of cancer with reduced side-effects. Besides characterization of genetic polymorphisms in patients, effective targeted delivery of siRNA molecules to cancer cells in vivo is vital in designing personalized medicine (74). The identification of new cancer-specific targets and pathways amenable to RNAi therapy would provide a greater impetus to the development of targeted therapies. Although challenging, the most attractive and noteworthy aspect of siRNA-based cancer drugs is that any cancer-associated gene can be targeted for cancer treatment, which may otherwise not be possible with small molecule or protein-based drugs. The use of multiple siRNAs targeting various cancer-specific genes from different cellular pathways would simultaneously silence several cancer-causing genes and, thus, be more potent in inhibiting malignant growth. The use of complex nanoparticles coated with receptor-specific ligands or monoclonal antibodies, harboring multiple therapeutic siRNAs would facilitate the specific targeting of cancer cells in vivo, thereby resulting in the development of more potent and effective therapies for cancer. These siRNA-guided therapies may reduce the time involved and be cost-effective, thereby aiding in the development of personalized medicine.

\section{References}

1. Napoli C, Lemieux C and Jorgensen R: Introduction of a chimeric chalcone synthase gene into petunia results in reversible co-suppression of homologous genes in trans. Plant Cell 2: 279-289, 1990.

2. Fire A, Xu S, Montgomery MK, Kostas SA, Driver SE and Mello CC: Potent and specific genetic interference by doublestranded RNA in Caenorhabditis elegans. Nature 391: 806-811, 1998.

3. Elbashir SM, Harborth J, Lendeckel W, Yalcin A, Weber K and Tuschl T: Duplexes of 21-nucleotide RNAs mediate RNA interference in cultured mammalian cells. Nature 411: 494-498, 2001.

4. Caplen NJ, Fleenor J, Fire A and Morgan RA: dsRNA-mediated gene silencing in cultured Drosophila cells: a tissue culture model for the analysis of RNA interference. Gene 252: 95-105, 2000.

5. Ui-Tei K, Zenno S, Miyata Y and Saigo K: Sensitive assay of RNA interference in Drosophila and Chinese hamster cultured cells using firefly luciferase gene as target. FEBS Lett 479: 79-82, 2000.

6. Stark GR, Kerr IM, Williams BR, Silverman RH and Schreiber RD: How cells respond to interferons. Annu Rev Biochem 67: 227-264, 1998.

7. Manche L, Green SR, Schmedt C and Mathews MB: Interactions between double-stranded RNA regulators and the protein kinase DAI. Mol Cell Biol 12: 5238-5248, 1992.

8. Minks MA, West DK, Benvin S and Baglioni C: Structural requirements of double-stranded RNA for the activation of 2',5'oligo(A) polymerase and protein kinase of interferon-treated HeLa cells. J Biol Chem 254: 10180-10183, 1979.

9. McCaffrey AP, Meuse L, Pham TT, Conklin DS, Hannon GJ and Kay MA: RNA interference in adult mice. Nature 418: 38-39, 2002.

10. Lewis DL, Hagstrom JE, Loomis AG, Wolff JA and Herweijer H: Efficient delivery of siRNA for inhibition of gene expression in postnatal mice. Nat Genet 32: 107-108, 2002.

11. Song E, Lee SK, Wang J, Ince N, Ouyang N, Min J, Chen J, Shankar P and Lieberman J: RNA interference targeting Fas protects mice from fulminant hepatitis. Nat Med 9: 347-351,2003.

12. Rose SD, Kim DH, Amarzguioui M, Heidel JD, Collingwood MA, Davis ME, Rossi JJ and Behlke MA: Functional polarity is introduced by Dicer processing of short substrate RNAs. Nucleic Acids Res 33: 4140-4156, 2005.
13. Tuschl T, Zamore PD, Lehmann R, Bartel DP and Sharp PA: Targeted mRNA degradation by double-stranded RNA in vitro. Genes Dev 13: 3191-3197, 1999.

14. Zamore PD, Tuschl T, Sharp PA and Bartel DP: RNAi: doublestranded RNA directs the ATP-dependent cleavage of mRNA at 21 to 23 nucleotide intervals. Cell 101: 25-33, 2000.

15. Hutvagner G: Small RNA asymmetry in RNAi: function in RISC assembly and gene regulation. FEBS Lett 579: 5850-5857, 2005.

16. Rand T, Petersen S, Du F and Wang T: Argonaute 2 cleaves the anti-guide strand of siRNA during RISC activation. Cell 123: 621-629, 2005.

17. Liu J, Carmell MA, Rivas FV, Marsden CG, Thomson JM, Song JJ, Hammond SM, Joshua-Tor L and Hannon GJ: Argonaute2 is the catalytic engine of mammalian RNAi. Science 305: 1437-1441, 2004.

18. Song JJ, Smith SK, Hannon GJ and Joshua-Tor L: Crystal structure of argonaute and its implications for RISC slicer activity. Science 305: 1434-1437, 2004.

19. Martinez J and Tuschl T: RISC is a 5-phosphomonoesterproducing RNA endonuclease. Genes Dev 18: 975-980, 2004

20. Schwarz DS, Tomari Y and Zamore PD: The RNA-induced silencing complex is a $\mathrm{Mg}^{2+}$-dependent endonuclease. Curr Biol 14: 787-791, 2004.

21. Hutvágner G and Zamore PD: A microRNA in a multipleturnover RNAi enzyme complex. Science 297: 2056-2060, 2002.

22. Dykxhoorn DM and Lieberman J: Knocking down disease with siRNAs. Cell 126: 231-235, 2006.

23. Soutschek J, Akinc A, Bramlage B, Charisse K, Constien R, Donoghue M, Elbashir S, Geick A, Hadwiger P, Harborth J, et al: Therapeutic silencing of an endogenous gene by systemic administration of modified siRNAs. Nature 432: 173-178, 2004.

24. Giladi H, Ketzinel-Gilad M, Rivkin L, Felig Y, Nussbaum O and Galun E: Small interfering RNA inhibits hepatitis B virus replication in mice. Mol Ther 8: 769-776, 2003.

25. Xia H, Mao Q, Eliason SL, Harper SQ, Martins IH, Orr HT, Paulson HL, Yang L, Kotin RM and Davidson BL: RNAi suppresses polyglutamine-induced neurodegeneration in a model of spinocerebellar ataxia. Nat Med 10: 816-820, 2004.

26. Diaz-Hernandez M, Torres-Peraza J, Salvatori-Abarca A, Moran MA, Gomez-Ramos P, Alberch J and Lucas JJ: Full motor recovery despite striatal neuron loss and formation of irreversible amyloid-like inclusions in a conditional mouse model of Huntington's disease. J Neurosci 25: 9773-9781, 2005.

27. Judge AD, Robbins M, Tavakoli I, Levi J, Hu L, Fronda A, Ambegia E, McClintock K and MacLachlan I: Confirming the RNAi-mediated mechanism of action of siRNA-based cancer therapeutics in mice. J Clin Invest 119: 661-673, 2009.

28. Santel A, Aleku M, Keil O, Endruschat J, Esche V, Durieux B, Löffler K, Fechtner M, Röhl T, Fisch G, et al: RNA interference in the mouse vascular endothelium by systemic administration of siRNA-lipoplexes for cancer therapy. Gene Ther 13: 1360-1370, 2006.

29. Landen CN, Chavez-Reyes A, Bucana C, Schmandt R, Deavers MT, Lopez-Berestein G and Sood AK: Therapeutic EphA2 gene targeting in vivo using neutral liposomal small interfering RNA delivery. Cancer Res 65: 6910-6918, 2005.

30. Grünweller A and Hartmann RK: RNA interference as a genespecific approach for molecular medicine. Curr Med Chem 12: 3143-3161, 2005.

31. Whitehead KA, Langer R and Anderson DG: Knocking down barriers: advances in siRNA delivery. Nat Rev Drug Discov 8: 129-138, 2009.

32. Tao W, South VJ, Zhang Y, Davide JP, Farrell L, Kohl NE, Sepp-Lorenzino L and Lobell RB: Induction of apoptosis by an inhibitor of the mitotic kinesin KSP requires both activation of the spindle assembly checkpoint and mitotic slippage. Cancer Cell 8: 49-59, 2005.

33. Liu X and Erikson RL: Polo-like kinase (Plk)1 depletion induces apoptosis in cancer cells. Proc Natl Acad Sci USA 100: 5789-5794, 2003

34. Grzelinski M, Urban-Klein B, Martens T, Lamszus K, Bakowsky U, Höbel S, Czubayko F and Aigner A: RNA interference-mediated gene silencing of pleiotrophin through polyethylenimine-complexed small interfering RNAs in vivo exerts antitumoral effects in glioblastoma xenografts. Hum Gene Ther 17: 751-766, 2006

35. Leenders F, Möpert K, Schmiedeknecht A, Santel A, Czauderna F, Aleku M, Penschuck S, Dames S, Sternberger M, Röhl T, et al: PKN3 is required for malignant prostate cell growth downstream of activated PI 3-kinase. EMBO J 23: 3303-3313, 2004. 
36. Aleku M, Schulz P, Keil O, Santel A, Schaeper U, Dieckhoff B, Janke O, Endruschat J, Durieux B, Roder N, et al: Atu027, a liposomal small interfering RNA formulation targeting protein kinase N3, inhibits cancer progression. Cancer Res 68: 9788-9798, 2008.

37. Davis ME, Zuckerman JE, Choi CHJ, Seligson D, Tolcher A, Alabi CA, Yen Y, Heidel JD and Ribas A: Evidence of RNAi in humans from systemically administered siRNA via targeted nanoparticles. Nature 464: 1067-1071, 2010.

38. Li YC, Kong LH, Cheng BZ and Li KS: Construction of influenza virus siRNA expression vectors and their inhibitory effects on multiplication of influenza virus. Avian Dis 49: 562-573, 2005.

39. Thanik VD, Greives MR, Lerman OZ, Seiser N, Dec W, Chang CC, Warren SM, Levine JP and Saadeh PB: Topical matrix-based siRNA silences local gene expression in a murine wound model. Gene Ther 14: 1305-1308, 2007.

40. Peer D, Park EJ, Morishita Y, Carman CV and Shimaoka M: Systemic leukocyte-directed siRNA delivery revealing cyclin D1 as an anti-inflammatory target. Science 319: 627-630, 2008.

41. Heidel JD, Yu Z, Liu JY, Rele SM, Liang Y, Zeidan RK, Kornbrust DJ and Davis ME: Administration in non-human primates of escalating intravenous doses of targeted nanoparticles containing ribonucleotide reductase subunit M2 siRNA. Proc Natl Acad Sci USA 104: 5715-5721, 2007.

42. Schiffelers RM, Ansari A, Xu J, Zhou Q, Tang Q, Storm G, Molema G, Lu PY, Scaria PV and Woodle MC: Cancer siRNA therapy by tumor selective delivery with ligand-targeted sterically stabilized nanoparticle. Nucleic Acids Res 32: e149, 2004.

43. DeVincenzo J, Cehelsky JE, Alvarez R, Elbashir S, Harborth J, Toudjarska I, Nechev L, Murugaiah V, Van Vliet A, Vaishnaw AK and Meyers R: Evaluation of the safety, tolerability and pharmacokinetics of ALN-RSV01, a novel RNAi antiviral therapeutic directed against respiratory syncytial virus (RSV). Antiviral Res 77: 225-231, 2008.

44. DiFiglia M, Sena-Esteves M, Chase K, Sapp E, Pfister E, Sass M, Yoder J, Reeves P, Pandey RK, Rajeev KG, et al: Therapeutic silencing of mutant huntingtin with siRNA attenuates striatal and cortical neuropathology and behavioral deficits. Proc Natl Acad Sci USA 104: 17204-17209, 2007.

45. Shen J, Samul R, Silva RL, Akiyama H, Liu H, Saishin Y, Hackett SF, Zinnen S, Kossen K, Fosnaugh K, et al: Suppression of ocular neo-vascularization with siRNA targeting VEGF receptor 1. Gene Ther 13: 225-234, 2006.

46. Vaishnaw AK, Gollob J, Gamba-Vitalo C, Hutabarat R, Sah D, Meyers R, deFougerolles T and Maraganore J: A status report on RNAi therapeutics. Silence 1: 1-13, 2010.

47. Castanotto D and Rossi JJ: The promises and pitfalls of RNA interference-based therapeutics. Nature 457: 426-433, 2009.

48. Braasch DA, Jensen S, Liu Y, Kaur K, Arar K, White MA and Corey DR: RNA interference in mammalian cells by chemicallymodified RNA. Biochemistry 42: 7967-7975, 2003.

49. Chiu Y and Rana T: siRNA function in RNAi: a chemical modification analysis. RNA 9: 1034-1048, 2003.

50. Layzer JM, McCaffrey AP, Tanner AK, Huang Z, Kay MA and Sullenger BA: In vivo activity of nuclease-resistant siRNAs. RNA 10: 766-771, 2004.

51. Cheng K, Ye Z, Guntaka RV and Mahato RI: Enhanced hepatic uptake and bioactivity of type a1(I) collagen gene promoterspecific triplex-forming oligonucleotides after conjugation with cholesterol. J Pharmacol Exp Ther 317: 797-805, 2006.

52. Zimmermann TS, Lee AC, Akinc A, Bramlage B, Bumcrot D, Fedoruk MN, Harborth J, Heyes JA, Jeffs LB, John M, et al: RNAi-mediated gene silencing in non-human primates. Nature 441: 111-114, 2006.

53. Guo P, Coban O, Snead N, Trebley J, Hoeprich S, Guo S and Shu Y: Engineering RNA for targeted siRNA delivery and medical application. Drug Deliv Rev 62: 650-666, 2010.

54. Kim DH and Rossi JJ: Strategies for silencing human disease using RNA interference. Nat Rev Genet 8: 173-184, 2007.

55. De Paula D, Bentley MV and Mahato RI: Hydrophobization and bioconjugation for enhanced siRNA delivery and targeting. RNA 13: 431-450, 2007.
56. Wu Y, Wang W, Chen Y, Huang K, Shuai X, Chen Q, Li X and Lian G: The investigation of polymer-siRNA nanoparticle for gene therapy of gastric cancer in vitro. Int J Nanomed 5: 129-136, 2010.

57. Yagi N, Manabe I, Tottori T, Ishihara A, Ogata F, Kim JH, Nishimura S, Fujiu K, Oishi Y, Itaka K, et al: A nanoparticle system specifically designed to deliver short interfering RNA inhibits tumor growth in vivo. Cancer Res 69: 6531-6538, 2009.

58. Kim SH, Jeong JH, Lee SH, Kim SW and Park TG: PEG conjugated VEGF siRNA for anti-angiogenic gene therapy. J Control Release 116: 123-129, 2006.

59. Jain KK: The role of nanobiotechnology in drug discovery. Drug Discov Today 10: 1435-1442, 2005.

60. Gao H, Shi W and Freund LB: Mechanics of receptor-mediated endocytosis. Proc Natl Acad Sci USA 102: 9469-9474, 2005.

61. Song E, Zhu P, Lee SK, Chowdhurym D, Kussman S, Dykxhoorn DM, Feng Y, Palliser D, Weiner DB, Shankar P, et al: Antibody mediated in vivo delivery of small interfering RNAs via cell-surface receptors. Nat Biotechnol 23: 709-717, 2005.

62. Nimjee SM, Rusconi CP and Sullenger BA: Aptamers: an emerging class of therapeutics. Annu Rev Med 56: 555-583, 2005.

63. Dassie JP, Liu XY, Thomas GS, Whitaker RM, Thiel KW, Stockdale KR, Meyerholz DK, McCaffrey AP, McNamara JO and Giangrande PH: Systemic administration of optimized aptamer-siRNA chimeras promotes regression of PSMAexpressing tumors. Nat Biotechnol 27: 839-849, 2009.

64. McNamara JO, Andrechek ER, Wang Y, Viles KD, Rempel RE, Gilboa E, Sullenger BA and Giangrande PH: Cell type-specific delivery of siRNAs with aptamer-siRNA chimeras. Nat Biotechnol 24: 1005-1015, 2006.

65. Li SD, Chen YC, Hackett MJ and Huang L: Tumor-targeted delivery of siRNA by self-assembled nanoparticles. Mol Ther 16: $163-169,2008$

66. Mendonca LS, Firmino F, Moreira JN, Pedroso de Lima MC and Simoes S: Transferrin receptor-targeted liposomes encapsulating anti-BCR-ABL siRNA or asODN for chronic myeloid leukemia treatment. Bioconjug Chem 21: 157-168, 2010.

67. Hu-Lieskovan S, Heidel JD, Bartlett DW, Davis ME and Triche TJ: Sequence-specific knockdown of EWS-FLI1 by targeted, nonviral delivery of small interfering RNA inhibits tumor growth in a murine model of metastatic Ewing's sarcoma. Cancer Res 65: 8984-8992, 2005.

68. Jackson AL, Bartz SR, Schelter J, Kobayashi SV, Burchard J, Mao M, Li B, Cavet G and Linsley PS: Expression profiling reveals off-target gene regulation by RNAi. Nat Biotechnol 21: 635-637, 2003.

69. Semizarov D, Frost L, Sarthy A, Kroeger P, Halbert DN and Fesik SW: Specificity of short interfering RNA determined through gene expression signatures. Proc Natl Acad Sci USA 100: 6347-6352, 2003.

70. Elbashir SM, Harborth J, Weber K and Tuschl T: Analysis of gene function in somatic mammalian cells using small interfering RNAs. Methods 26: 199-213, 2002.

71. Hornung V, Guenthner-Biller M, Bourquin C, Ablasser A, Schlee M, Uematsu S, Noronha A, Manoharan M, Akira S, de Fougerolles A, et al: Sequence-specific potent induction of IFN-alpha by short interfering RNA in plasmacytoid dendritic cells through TLR7. Nat Med 11: 263-270, 2005.

72. Karikó K, Bhuyan P, Capodici J,Ni H, Lubinski J, Friedman H and Weissman D: Exogenous siRNA mediates sequence independent gene suppression by signaling through toll-like receptor 3. Cells Tissues Organs 177: 132-138, 2004.

73. Judge AD, Sood V, Shaw JR, Fang D, McClintock K and MacLachlan I: Sequence dependent stimulation of the mammalian innate immune response by synthetic siRNA. Nat Biotechnol 23: 457-462, 2005.

74. Singh D, Kashyap A, Pandey RV and Saini KS: Novel advances in cytochrome P450 research. Drug Discov Today 16: 793-799, 2011. 